Research Article

\title{
Innovative new method to test skill of bioassay in postgraduate students during doctor of medicine pharmacology examination using objective structured practical examination and animal experiment software
}

\author{
Naresh D. Balani*, Prabodh Anant Wankhade
}

Department of Pharmacology, Government Medical College, Akola, Maharashtra, India

Received: 08 June 2016 Accepted: 04 July 2016

*Correspondence to: Dr. Naresh D. Balani, Email: drnareshbalani@ gmail.com

Copyright: (C) the author(s), publisher and licensee Medip Academy. This is an openaccess article distributed under the terms of the Creative Commons Attribution NonCommercial License, which permits unrestricted noncommercial use, distribution, and reproduction in any medium, provided the original work is properly cited.

\begin{abstract}
Background: Despite the guidelines for discontinuation of dissection and animal experimentation and introduction of use of alternatives to animal experimentation, Maharashtra University of Health Science, Nashik has not modified the exam pattern by shifting the emphasis on to use of animal experiment software. In one study on importance of bioassay in career, it has been reported that $96.6 \%$ did not use their knowledge of Bioassay during their 10 years of post MD career, whether in pharmaceutical industry or in academics. $16.6 \%$ feel that experiment on bioassay should be continued in the current state. $76.7 \%$ of them wish it to be modified to a dose response curve (DRC).

Methods: We have designed an innovative technique by combination of OSPE, mounting skill testing using simulation and animal experiment software. This technique serves the purpose of testing the skill of bioassay methodology in four postgraduate students receiving training. The animal was not sacrificed and not dissected in this technique.

Results: All the four test subjects could understand well about task to be done. The totals out of 140 were 87.5, 83, 70.5 and 55 respectively. The corrected marks out of 150 was calculated and shown in the table. 3 out of 4 passed in the examination as shown in observation table.

Conclusions: This method is good alternative to the traditional method of bioassay, as there is no need of sacrificing and dissecting the animal for the sake of this less important experiment.
\end{abstract}

Keywords: OSPE, Simulated tissue mounting, Animal experiment software, bioassay, MD exam

\section{INTRODUCTION}

It is documented that bioassay method is relied upon over chemical assay as it is the assessment on the living organism, even if it is more laborious, more troublesome, more expensive, less elaborate and less accurate. ${ }^{1}$ Bioassay has been considered as helpful in the commercial production of drugs in absence of chemical assays and also important from clinical point of view as it may help in diagnosis e.g. gonadotropins for pregnancy. It serves as research tool being the quantitative part of screening procedure. ${ }^{1}$

In the current situation it has been advised in a letter addressed to directors/principals/deans of medical colleges and pharmacy colleges from the undersecretary in the Ministry of Health and Family Welfare with a subject heading "guidelines for discontinuation of dissection and animal experimentation and introduction of use of alternatives to animal experimentation." Subsequently university grants commission (UGC) has formulated and circulated letter to colleges teaching zoology and other life sciences. ${ }^{2}$

Bioassay experimentation is important and major experimental exercise which carries 150 marks in MD Pharmacology exam of Maharashtra University of Health sciences (MUHS) Nashik. Subsequent to this the efforts at different centres are being taken to find alternative technique/method to fulfil the criteria of performing bioassay in MD examination under MUHS Nashik, wherein bioassay of acetylcholine and histamine on isolated chick/cock ileum have been demonstrated and 
recommended as alternative methods. ${ }^{3,4}$ However this also requires killing of the innocent animal although easy availability. The problems possible with this method are

- Inconsistent contractile responses to the graded doses

- Absence of evaluation of dissection part

- Non-responsiveness of piece mounted.

All these will lead to non-completion of bioassay and will defeat the institutional as well as university objectives. There are suggestions that OSPE can be used as alternative method. Oral examination is for assessing knowledge, other methods like OSPE, directly observed methods etc., should be used. ${ }^{5}$ Similarly use of animal experiment software can be helpful in achieving objectives as per the respective Ministry and university grant commission. As it is shown in a survey that $96 \%$ respondents felt that Pharmacology curriculum emphasizes on becoming good undergraduate teachers, and $83 \%$ felt that it gives inadequate practical training in research methodology. ${ }^{6}$

In the present scenario it appears that a new method is deemed necessary to save the life of animal, to fulfil the objective of bioassay experimentation during MD pharmacology exam and also to test the basic skill required for bioassay in examinees. A letter from health education beuro [HEB/DGF/ 2016/914 Date: 4/1/2016] indicates that the undergraduate and postgraduate level animal experiments are to be done on computer using computer assisted learning software.

\section{METHODS}

We have designed the method which is combination of Objective Structured Practical Examination OSPE, mounting and software. There is no need to sacrifice innocent animal. The objective is to fulfil the criteria of long exercise bioassay for the MD examination as mentioned MUHS syllabus. $^{7}$

\section{OSPE for (evaluation of dissection)}

\section{Stage 1}

Incorporates use of objective structured practical examination (OSPE) using paper pencil technique. There will be six stations i.e. station 1 to 6 . Each station will be containing questions regarding sequential steps of dissection of animal. The check list containing correct answer and marks thereon will separately be prepared for purpose of use by examiner. Each question will be carrying 2-6 marks and total assigned marks are 40. The candidates appearing in the exam will be provided the worksheet individually and will be asked to visit each station to write answer of questions. Their answers on the worksheet will be evaluated by the team of examiners and the scores will be recorded for stage 1 of each candidate separately.

\section{Objective Structured Practical Examination (OSPE) Bioassay of histamine on guineapig Answer sheet for students}

Examination:

Date:

Time:

Roll. No......
Roll No.....

Max. Marks: 40

Marks obtained

Max. Marks (12)

\section{STATION 1}

\section{Mention procedure of preparing physiological salt solution}

Station 1: Check list for examiners

I. Weighing balance is balanced.1.5

II. Chemical required are drawn from shelf. 1.0

III. Quantity weighed of each required chemical for 5 litre. 5.0

IV. 5 litre distilled water taken in jar and chemicals added to it. 2.0

V. All chemicals dissolved in 5 litre distilled water by stirring. 1.0

VI. Oxygenate the physiological salt solution (Tyrode/M. Ringer). 1.5
Marks obtained 
Roll. No

\section{STATION 2}

I. How will you keep constant volume of perfusate for each cycle?

II. How will you balance the lever?

III. How will you maintain temperature of perfusate in organ bath assembly?

IV. How will you stretch the piece mounted?

V. How will you minimize friction of pointer with paper?

VI. How will you fix duration of cycle-Mention Particulars?

Marks obtained

\section{Check list for examiners}

\section{STATION 2}

I. Marking organ bath at $20 \mathrm{ml}$ capacity using marker pen. (1.0)

II. $\quad 70 \%$ length arm of lever towards drum, $30 \%$ toward other side. (2.0)

III. Using plasticin, tightening fulcrum screw, maintaining horizontal position of lever setting thermostat at $37{ }^{0} \mathrm{C}-\mathrm{Outer}$ bath fluid temp. (1.0)

IV. Suspending $500 \mathrm{mg} \mathrm{Wt.} \mathrm{using} \mathrm{thread} \mathrm{from} \mathrm{long} \mathrm{arm} \mathrm{of} \mathrm{lever.} \mathrm{(1.0)}$

V. Adjusting four screws at bottom of kymograph + tapping. (1.0)

VI. 3 minutes cycle: 0 minute (Elevate wt., Start drum), 1minute (Add drug). (6.0) 1.5 minute (Suspend wt., give wash), 0 minutes (elevate wt., start drum)

Roll. No

Max. Marks (3)

\section{STATION 3}

I. Name the procedure to make the animal unconscious

II. Name the area for hard blow to make animal unconscious

III. Write name of perfusion fluid/Physiological salt solution

IV. Which part of neck is cut?

Marks obtained.

\section{Checklist for examiner}

\section{STATION 3}

I. Cerebral concussion. (1.0)

II. Cranium-Just proximal to nape of neck. (1.0)

III. Tyrode solution/Mammalian ringer. (1.0)

IV. Antero-lateral Carotids and trachea. (1.0) 
Roll. No

\section{STATION 4}

I. How many fingers should you use to hold animal and grip which body part?

II. Write anatomical basis of such type of hold?

III. How will you kill animal?

IV. Write the pattern of incision?

Marks obtained

\section{Checklist for examiner}

\section{STATION 4}

I. Four fingers on one side and thumb on other side of loin (lumbosacral area). (1.0)

II. Head down -Hanging upside down. (1.0)

III. Hard blow on head and cutting the throat. (1.0)

IV. Ventral midline incision on abdominal wall. (1.0)

Roll. No

\section{STATION 5}

I. Name the organ which is mounted in isolated organ bath assembly?

i. Name the tissue

ii. Receptors involved

iii. Nature of drug and

iv. Response (s) to be observed?

Marks obtained

\section{Checklist for examiner}

\section{STATION 5}

I. Isolated 1" piece of ileum of Guinea pig. (1.0)

i. Smooth muscle of intestine. (0.5)

ii. Muscarinic receptors (M3). (0.5)

iii. Histamine (Agonist). (0.5)

iv. Contractile graded dose response. (0.5)

Roll. No

\section{STATION 6}

I. How the organ/Tissue is mounted in isolated organ bath assembly? 
Marks obtained.

\section{Checklist for examiner}

\section{STATION 6}

I. $\quad 1$ ' piece of ileum (6" proximal to ileo-caecal junction) taken on index finger distal phalynx area. (2.0)

II. Thread needle, tie thread to both ends to anti-mesentric borders. (1.5)

III. Using stellete fix one end to organ bath outlet and other end to frontal writing lever. (1.5)

\section{Evaluation of mounting skill}

Stage 2

The candidates who completed the work in stage 1 will be subjected to tissue mounting exercise. The simulation of 1 inch piece of ileum will be provided to them and they will be asked to mount it in the assembly using prerequisites. The questions will be asked by examiner on different aspects about assembly, prerequisites, precautions and other relevant aspects and will be awarded the marks of stage 2 out of 30 .

\section{Evaluation of bioassay skill using software}

Stage 3

The exercise of finding the strength of unknown solution can be assigned to the candidates. The candidates are asked to find out the strength of unknown solution based on provision in animal experiment software. They are free to go for interpolation, 3 point assay, 4 point assay whichever is feasible. They are asked to complete the calculation manually using log dose response curve and also by computerized manner (for matching) given in software. The difference between two final calculations (i.e. matching versus any of above assay method) is checked by examiners. The questions can be asked on this graphical and calculation aspects and finally marks will be awarded out of 70 and was then corrected to out of 80 . The scored marks of candidates of stage 1,2 , and 3 will be summed up and the result (passed or failed) on this part of examination can be arrived (Keeping 75 as minimum marks for passing).

\section{RESULTS}

3 out of 4 residents undergoing MD pharmacology training at GMC Akola scored more than $50 \%$ out of total 150 by this method of examination without sacrificing animal. The scores in first part i.e. OSPE were found to be $30.5,37,32.5$ and 7 respectively out of total 40. In mounting of tissue part (stage 2) the scores were $12,13,6$ and 13 respectively out of total 30 . Whereas estimation of strength of unknown solution using animal experiment software (stage 3), the scores were 45, 50, 35 and 35 respectively. The totals out of 140 were $87.5,83$, 70.5 and 55 respectively. The corrected marks out of 150 was calculated and shown in the table. The observations are shown in Table 1. Showing the scores of participants stage wise in bioassay experiment without using animal.

Table 1: The scores of participants stage wise in bioassay experiment without using animal.

\begin{tabular}{|llllll|}
\hline Name of participants & Stage 1 (OSPE) & Stage 2 (mounting) & Stage 3 (software) & Total (150) & Remarks \\
\hline K. I. & 30.5 & 12 & 51.42 & Passes & 93.9 \\
\hline R. H. & 27 & 6 & 57.14 & Passes & Passes \\
\hline R. R. & 22.5 & 13 & 40 & 75.5 & 60 \\
\hline S. Y. & 7 & 13 & 40 & Fails \\
\hline
\end{tabular}

Abbreviations of full name of participants.

All the four participants first carried out calculations of matching methods. Subsequent to it, they were asked to calculate manually for interpolation method using graph paper and log dose response curve.

S1 and S2 stand for 2 selected doses of standard while T represents height of contraction with test solution, interpolated on log dose response curve.

\section{Advantages}

- The problems of non-responsiveness, inconsistency of responses which can spoiled the experiment and result in the conventional method is definitely overcome

- Skill of bioassay experiment and the sequence of the work to be done can be evaluated

- Subjectivity can be overcome as the record can be taken on black and white making it more objective

- Graded dose responses can definitely be obtained using animal experiment software

- This way the new method can be a good substitute of conventional bioassay method, the most important life of innocent animal is saved. 


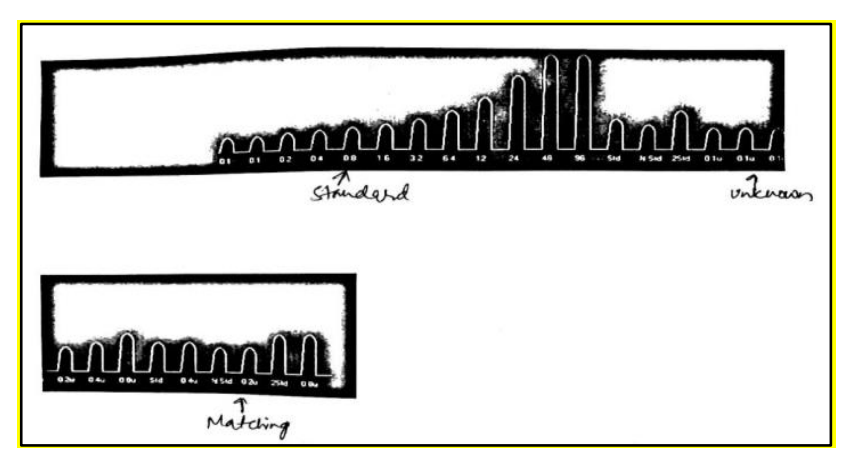

Figure 1: Graded doses responses with standard and responses of unknown strength solutions during matching method using software.

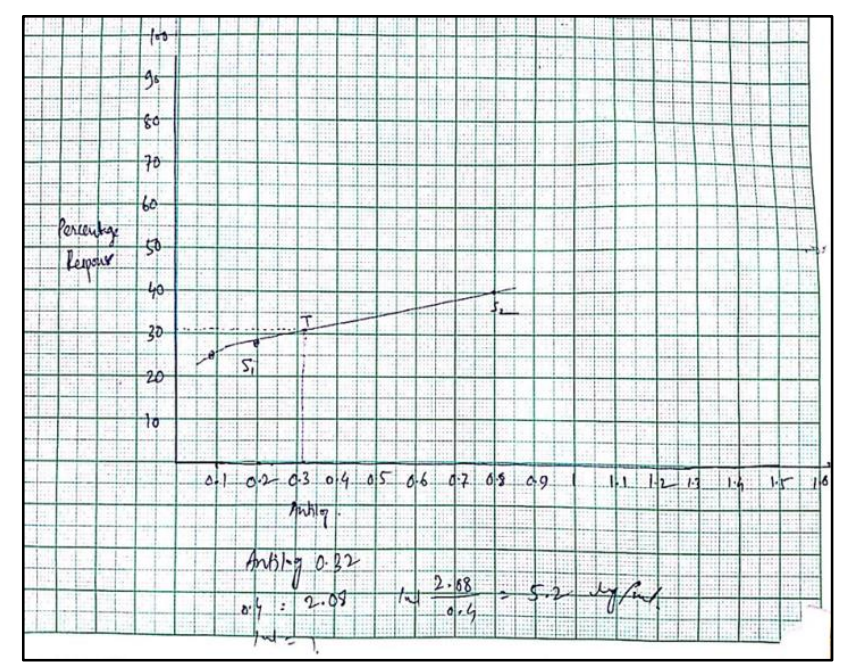

Figure 2: Manual calculations to estimate strength of unknown histamine solution by interpolation method using simulation and log dose response curve.

\section{DISCUSSION}

Using this 3 stage new technique of assessing bioassay skill in candidates during MD pharmacology examination fulfils the criteria of conductance of long exercise during examination without sacrificing the animal. We have exposed 4 postgraduate students registered for MD pharmacology in our department. All of them have successfully completed their work at these 3 stages. There was reasonable difference of about 21 to $27 \%$ where in interpolation method conventionally is supposed to be more accurate than matching. However such method cannot be implemented in analytical laboratories where the test solution has to be analysed for actual biological activity per unit volume using conventional bioassay methods.

The volumes of unknown test solution used were same which matched with the corresponding height of the known strength dose using software. This dose of unknown in volume and its response (height in $\mathrm{mm}$ ) were used for manually calculations in interpolation method. Earlier some other workers have documented possibility of bioassay of acetylcholine using isolated chick ileum. Bioassay of histamine using chick ileum has also been reported. Methodologically isolated guineapig ileum is conventionally described as method of bioassay of histamine in isolated tissue experiment book. We cannot spare the life of an animal and animal has to be sacrificed in method described in book.

By using this 3 stage innovative method we can save the life of an innocent animal without adverse impact on the work plan as well as learning of PG students doing MD pharmacology. At the same time knowledge about dissection and physiological salt solution preparation can be tested by OSPE which will not be possible using chick ileum brought from the market. As 3 out of 4 participants passed (in observation table), we suggest that this method may be implemented and approved by universities and medical institution for effective learning purposes only. Although the log dose response curve less steep, nevertheless it serves the purpose in interpolation method.

Mulkalwar S, Rane B, Behera L in 2014 have reported that out of 30 participants, $29(96.6 \%)$ did not use their knowledge of bioassay during their 10 years of post MD career, whether in pharmaceutical industry or in academics. Only 5 of them $(16.6 \%)$ feel that experiment on bioassay should be continued in the current state. $76.7 \%$ of them wish it to be modified to a dose response curve (DRC). $6.71 \%$ feel that it should be totally scrapped.8 However the scientists may advocate use of animals for research to facilitate new discoveries, although animal handling and use is not uniformly possible in different laboratories and institutions. ${ }^{9}$

\section{The limitations of this study were}

- Stage 1 evaluation requires team work as separate observer/invigilator is required to be present at 1 each of the seventh stations

- Evaluation time will be more than the conventional bioassay method

- Biological activity is not taken into consideration in the contractile responses obtained by using animal experiment software

- This new technique is meant only for assessment of skilled developed in the candidates appearing for examination only (and not for analytical laboratories).

\section{ACKNOWLEDGEMENTS}

Authors would like to thankful to the dean GMC Akola for his time permission to design and carry out the method and its outcome. We are also thankful to 4 Postgraduate students of Dept. of pharmacology GMC, Akola who cooperated by participating as test subject.

\section{Funding: No funding sources Conflict of interest: None declared Ethical approval: Not required}




\section{REFERENCES}

1. Goyal RK, Importance of bioassay. Pharmacology Principles and Methods of Bioassay. 2008;1(1):1-2.

2. Gitanjali B. Are we going to allow the last nail on the coffin of animal experimentation to be nailed?. J Pharmacol Pharmacother. 2012;3:215-6.

3. Saedi M, Alternative to laboratory animals for isolated tissue experimentation using chicken ileum preparation. World Journal of Pharmaceutical Research. 2016;5(2):738-48.

4. Parthasarathy N. Isolated chick ileum for bioassay of acetylcholine. Indian Journal of Pharmacology. 2013;45(3):313.

5. Badyal DK, Desai C, Tripathi SK, Dhaneria SP, Chandy SJ, Bezbaruah BK. Postgraduate pharmacology curriculum in medical institutions in
India: Time for need-based appraisal and modifi cations. Indian J Pharmacol. 2014;46:584-9.

6. Chakraborty A. A survey on postgraduate pharmacology education in India. Indian $\mathrm{J}$ Pharmacol. 2010;42:253-4.

7. Postgraduate curriculum in MD (pharmacology and therapeutics), Maharashtra University of Health Sciences. Passed by Academic Council (Resolution No. 365/2006) dtd. 28/06/2006. Available at http://www.muhs.ac.in/upload/syllabus/md_pharmac ology.pdf.

8. Mulkalwar S, Rane B, Behera L. Restructuring the syllabus for MD Pharmacology: Retrospection of bioassay. Med J DY Patil Univ. 2014;7:473-6.

9. Badyal DK, Desai C. Animal use in pharmacology education and research: the changing scenario. Indian J Pharmacol. 2014;46:257-65.

Cite this article as: Balani ND, Wankhade PA. Innovative new method to test skill of bioassay in postgraduate students during doctor of medicine pharmacology examination using objective structured practical examination and animal experiment software. Int J Basic Clin Pharmacol 2016;5:1622-8. 